\title{
Ectodermal dysplasia associated with autoimmune disease
}

\author{
S. O. HUNG AND A. PATTERSON \\ From St Paul's Eye Hospital, Old Hall, Street, Liverpool L3 9PF
}

SUMMARY A case is reported of hereditary ectodermal dysplasia with corneal involvement associated with polyendocrinopathy and pernicious anaemia. The presence of autoantibodies to various endocrine organs and ocular tissues is confirmed. This suggests that ectodermal dysplasia may be an autoimmune disease.

Ectodermal dysplasia is known to affect various tissues of embryonic ectodermal origin. The main abnormality affects skin and its appendages and teeth. There are various forms of ocular manifestation, principally involving ectodermal structures such as the cornea, lacrimal systems, lens, and retina. Related disorders of skeletal abnormality and cleft palate have been described. This paper reports an association of ectodermal dysplasia with autoimmune diseases.

\section{Case report}

The patient, a male aged 22 years, was born at full term following normal pregnancy. At the age of 18 months he was seen by dermatologist for loss of hair, eyebrows, and eyelashes together with nail dystrophy. At the age of 10 years he presented to a paediatrician with pallor and anorexia; pernicious anaemia was diagnosed. Four years later he developed symptoms of excessive water drinking, salt craving, nocturia, and enuresis. A water deprivation test confirmed the diagnosis of cranial diabetes insipidus. He was first seen by an ophthalmologist at the age of 14 years with symptoms of photophobia and chronic irritation of the eyes. The initial sign was superficial punctate keratitis, which did not respond to various topical antibiotics and steroids. He was followed up in the eye clinic for 2 years, during which his vision remained good at $6 / 6$ in each eye. He was then lost to follow-up in the eye clinic because of his poor general health. At the age of 17 years Addison's disease was diagnosed. Two years later he developed attacks of tetany and was found to have hypoparathyroidism. He was seen again by an ophthalmologist at the age of 18 years, when upper-third corneal pannus was noted Correspondence to $S$. O. Hung. in both eyes; since then the corneal pannus had progressed very slowly.

The parents are normal, but an elder brother had Addision's disease and diabetes insipidus and died at the age of 15 years after fulminating chicken pox.

General examination showed total apopecia (Fig. 1). The skin was smooth and soft; the nails were thick

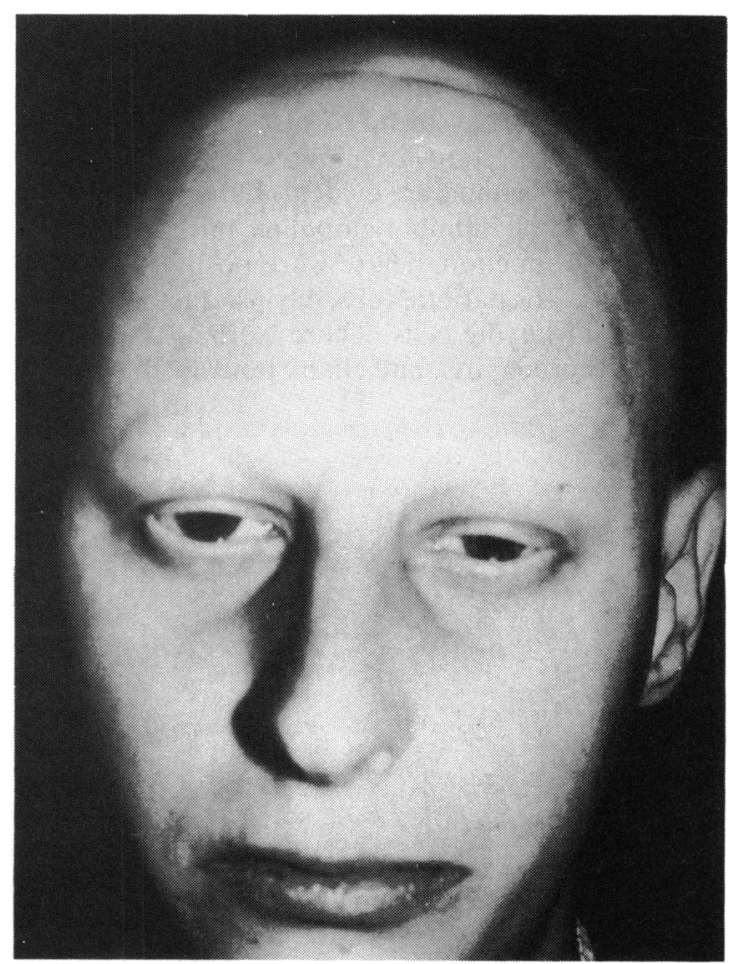

Fig. 1 Alopecia totalis. 


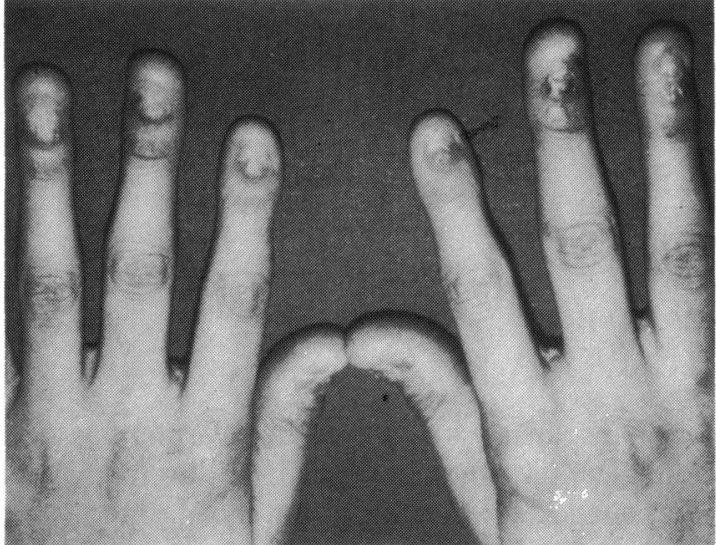

Fig. 2 Nail dystrophy.

and malformed (Fig. 2). The teeth were fragile and malarranged (Fig. 3). The patient was of short stature and had bilateral cryptochidism. His intelligence was normal.

Ocular examination revealed total loss of eyebrows and only 2 to 3 rudimentary eyelashes remained on the upper lids. The lacrimal puncta were present and patent. The Meibomian gland openings were present. Visual acuities were right $6 / 9$ with $+0.50 \mathrm{DS}$ and left $6 / 12$ with $+0 \cdot 50 \mathrm{DS}$. Corneal pannus was present in each eye covering the upper third of the cornea with superficial blood vessels invading supepithelium and superficial corneal stroma. The deep stroma was not involved (Fig. 4). Schirmer's test gave right $9 \mathrm{~mm}$, left $19 \mathrm{~mm}$, of wetting in 5 minutes. No abnormalities of iris, lens or retina were evident. Laboratory studies showed normal immunoglobulins but defective $\mathrm{T}$ lymphocyte function. There were positive autoantibodies to gastric parietal cells, intrinsic factor, adrenal cortex, and Leydig cells. There were also autoantibodies to cornea, iris, and ciliary body (Table 1).

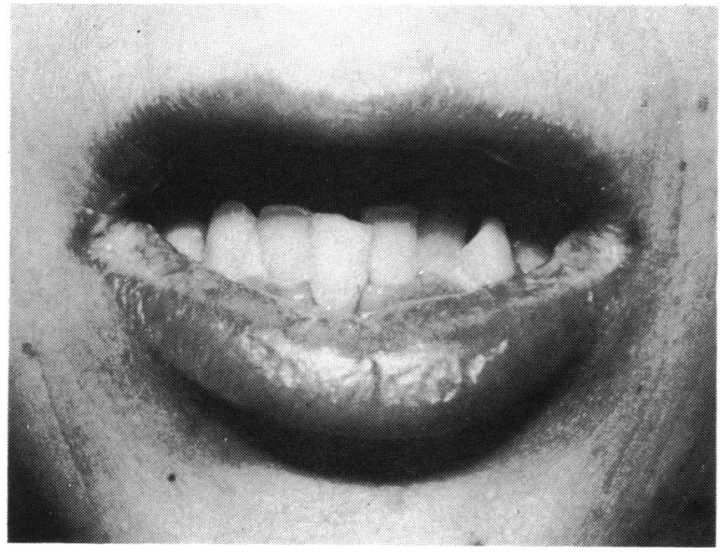

Fig. 3 Malarranged teeth; note chipped central incisor.

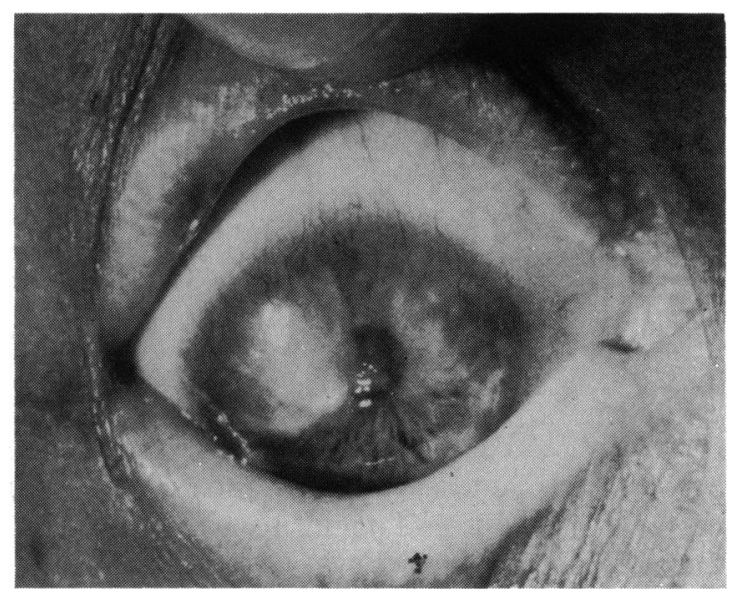

Fig. 4 Corneal pannus.

\section{Discussion}

Ectodermal dysplasia is a genetically determined syndrome with widespread abnormalities of ectodermal structures characterised by a triad of hypohydrosis, hypotrichosis, and hypodontia.' It was first described as early as 1792 by Danz, ${ }^{2}$ later by Widderburn $^{3}$ in 1838 and Thurnam ${ }^{4}$ in 1848 . The mode of inheritance of this syndrome is not fully resolved. Cockayne ${ }^{5}$ considered 2 types of inheritance-autosomal dominant and sex-linked recessive. The latter may explain the preponderance of males being affected. ${ }^{6}$ Kline $^{7}$ suggested that ectodermal dysplasia was transmitted as a dominant trait with sex-affected expressivity. Ectodermal dysplasia may present with various degrees of severity; in the severe form it may be associated with gross skeletal deformities-for example, ectrodactyly, ectodermal dysplasia, and cleft lip and

Table 1 Autoantibodies

Anti-nuclear

Anti-nucleolar

Anti-mitochondrial

Anti-smooth muscle

Anti-salivary gland

Anti-ncural

Anti-reticulin

Skin

Thyroid

Gastric parictal cells

Intrinsic factor

Adrenal cortex

Leydig cells

Pancreatic islet cells

Pituitary

Parathyroid

Cornea

Iris

Ciliary body negative

negative

negative

negative

negative

negative

negative

negative

negative

positive

positive

positive

positive

negative

negative

negative

positive

positive

positive 
palate. ${ }^{8-10}$ Ectodermal dysplasia is associated with Friedreich's ataxia and Horner's syndrome of the central type together with nystagmus. ${ }^{1}$ However, the association with autoimmune disease has not been reported hitherto.

Disordered structures derived from embryonic ectoderm cause various ocular symptoms. Corneal changes with pannus formation, ${ }^{12}$ as in this case, and Groenouw type I granular dystrophy ${ }^{7}$ have been described. Lacrimal system anomalies with lacrimal punctal atresia, ${ }^{81314}$ cataracts, ${ }^{1315}$ and chorioretinal atrophy ${ }^{15}$ have also been reported.

Wilson et al. ${ }^{12}$ recorded the histopathology of the corneal pannus removed at superficial keratectomy: eosinophils and plasma cells were found in the pannus. They suggested that immune mechanisms may be a factor in the corneal changes. Alopecia areata had been found to be associated with a high incidence of autoantibodies to smooth muscle, ${ }^{16}$ indicating its association with autoimmunity. It is interesting that the present case has demonstrated the association of alopecia totalis and corneal pannus with autoimmune polyendocrine disease and pernicious anaemia. Indeed, the presence of autoantibodies to gastric parietal cells, intrinsic factor, adrenal cortex, Leydig cells, cornea, iris, and ciliary body were confirmed. Thus ectodermal dysplasia may be an autoimmune disease affecting structures developed from embryonic ectodermal cells.

We thank Dr C. S. Smith of Alder Hey Children's Hospital, Liverpool, for allowing us to quote the result of autoantibodies to endocrinc organs. We are also grateful to $\operatorname{Dr} \mathrm{A}$. H. S. Rahi of The Institute of Ophthalmology for carrying out the test for ocular autoantibodics.

\section{References}

1 Weech AA. Hercditary ectodermal dysplasia (congenital cctodermal defect): a report of two cases. Am J Dis Child 1929; 37: 766-90.

2 Danz. Concerning men without hair or teeth. Stark's Arch Geburt 1792; 5: 684 (quoted in Wilson FM, et al. ${ }^{12}$ ).

3 Widdenburn W. Letter to Charles Darwin. In: Darwin CR: The variations of animals and plant under domestication. New York: Appleton, 1894: 2: 319

4 Thurnam J. Two cases in which the skin, hair, and tecth are very imperfectly developed. $R$ Med Chir Soc Trans (London) 1848; 31: 71.

5 Cockaync EA. Inherited abnormalities of the skin and its appendages. London: Oxford University Press, 1933: 218.

6 Scagle TB. Anhidrotic hereditary ectodermal dysplasia. J Pediatr 1954; 45: 688-91.

7 Kline AH, Sidbury JB, Richter CP. The occurrence of ectodermal dysplasia and corneal dysplasia in one family. $J$ Pediatr 1959; 55: 355-66.

8 Kaiser-Kupper M. Ectrodactyly, ectodermal dysplasia, and clefting syndrome. Am J Ophthalmol 1973; 76: 993-8.

9 Rudiger RA, Hasse W, Passarge E. Association of ectrodactyly, cctodermal dysplasia and cleft lip-palate. Am J Dis Child 1970; 120: $160-3$.

10 Baum JL, Bull MJ. Ocular manifestations of the ectrodactyly, ectodermal dysplasia, cleft lip-palate syndromc. $A m \mathrm{~J} O p h$ thalmol 1974; 78: 211-6.

11 Rook A, Wildinson DS, Ebling FJG. Textbook of dermatology. 3rd ed. Oxford: Blackwell, 1979: 1: 113-5.

12 Wilson FM, Grayson M, Pieroni D. Corneal changes in ectodermal dysplasia, case report, histopathology, and differential diagnosis. Am J Ophthalmol 1973; 75: 17-26.

13 Beckerman BL. Lacrimal anomalies in anhidrotic ectodermal dysplasia. Am J Ophthalmol 1979; 75: 728-30.

14 Liakos GM. Anhidrotic ectodermal dysplasia with lacrimal anomalies. Br J Ophthalmol 1979; 63: 520-2.

15 Gregory IDR. Congenital ectodermal dysplasia. Br J Ophthalmol 1955; 39: 44-7.

16 Main RA, Robbic RB, Gray ES, Donald D, Horne CHW. Smooth muscle antibodies and alopecia areata. Br J Dermatol 1975; 92: 389-93. 